\title{
Preparing for Virtual Student Teaching: a Presence + Experience Design Case
}

\author{
Jacob A. Hall ${ }^{1}$ (D) $\cdot$ Christine Widdall $^{1} \cdot$ Jing Lei $^{2}$ \\ Accepted: 14 August 2021 / Published online: 31 August 2021 \\ (C) Association for Educational Communications \& Technology 2021
}

\begin{abstract}
As online classrooms become more commonplace in K-12 education, teacher education programs seek to better prepare candidates for these contexts and are considering ways to address this additional preparation within their curricula. This article presents a design case of a 2-credit, 10-day, online course that was created to prepare 237 pre-service teachers for student teaching in online environments during the Fall 2020 semester. The Presence + Experience framework guided the design process in this case as designers sought to build a community of online learners within a highly experiential learning environment. This article details the design process with this framework along with its challenges, designers' experiences, and the resulting product.
\end{abstract}

Keywords Design case $\cdot \mathrm{K}-12$ online $\cdot$ Presence + experience framework $\cdot$ Teacher preparation

While the need to prepare K-12 teachers for online environments predated the COVID-19 pandemic (Moore-Adams et al., 2016), tightly sequenced teacher education programs, differing faculty perspectives on the efficacy of online learning, and minimal state certifications for online teaching have presented barriers to including such preparation in teacher education programs (Barbour \& Archambault, 2013). Across the United States, the need for teachers to be trained for online contexts has also varied; as of the 2017-2018 academic year, 11 states still had no full-time virtual schools (Molnar et al., 2019). Furthermore, states with full-time virtual schools reported challenges with training, recruiting, and evaluating online teachers (Molnar et al., 2019). The rush to distance education resulting from the global pandemic further magnified

Jacob A. Hall

jacob.hall@cortland.edu

Christine Widdall

chris.widdall@cortland.edu

Jing Lei

jlei@syr.edu

1 Childhood/Early Childhood Education Department, SUNY Cortland, P.O. Box 2000, Education Building, Room 1247, Cortland, NY 13045, USA

2 School of Education, Syracuse University, 252 Huntington Hall, Syracuse, NY 13244, USA this need to train teachers for online environments and necessitated a more immediate response from teacher education institutions (Trust \& Whalen, 2020).

Amidst the yet emerging research on developing teachers for K-12 virtual education, programs worked within compressed timelines to design and implement interventions that could prepare pre-service teachers (PSTs) for online field placements (Cirillo et al., 2020; Keefe, 2020). Given this upsurge, there is an acute need for design cases that elaborate on the instructional design processes and resulting products intended to prepare PSTs for online teaching. Extracting knowledge from these "known solutions and their affordances" (Howard et al., 2012, p. 34) can guide future designs of similar interventions and also contribute to the fields' knowledge base of much needed "literature that captures the complexity of design decisions" (Howard et al., 2012, p. 36).

In this study, we present a design case that documents the design of an online course for PSTs that focused on preparing them to teach in online K-12 environments. Proposed in the summer of 2020 as an ad hoc course to support PSTs who would likely complete field experiences in online or hybrid settings, course designers had approximately one month to design and develop the course from its proposal to the initial implementation. The course, therefore, was required of all PSTs across nine teacher education programs who would be student teaching during the Fall 2020 semester. Half the PSTs 
had no prerequisite coursework related to technology integration, while the remaining half had completed a 3 -credit hour course focused on educational technology in face-to-face classrooms. This prerequisite educational technology course, which emphasized in-person technology integration, was framed by the International Society for Technology in Education's (ISTE) Educator Standards (2017), but the learning outcomes and content for the course in this design case were based on the 2019 National Standards for Quality Online Teaching (NSQOT) as they more distinctly apply to online teaching competencies. Experts in online teaching developed the NSQOT standards, and these standards have been widely used to frame online teaching, courses, and programs (Virtual Learning Leadership Alliance \& Quality Matters, 2019). Thus, the NSQOT standards were highly suitable for the course goals.

As for a process model, the Presence + Experience Framework (PEF) informed the course design in this case (Dunlap et al., 2016). The PEF integrates the descriptive nature of the Community of Inquiry (CoI) Framework (Garrison et al., 2000) with Experiential Learning Theory's prescriptive phases of instruction (Kolb, 1984). In proposing their model, Dunlap et al. (2016) noted that attending to the social, teaching, and cognitive presences in online course design engages "students and teachers in community-oriented, knowledgebuilding interactions" (p. 146), which have been shown to lead to improved learning outcomes (Castellanos-Reyes, 2020; Johnson et al., 2019). Situating these interactions within cycles of Experiencing, Examining, Explaining, and Applying is intended to more effectively sequence and organize instruction; facilitate student interactions with peers, content, and the instructor; and systematically inform the incorporation of CoI strategies (Dunlap et al., 2016; Kolb, 1984). Clearly grounded on widely applied design literature, the PEF exhibits strong potential for informing online design, yet there is scarce literature documenting the processing of designing with the PEF or the impacts of its design products.

Thus, this design case seeks to detail how the PEF was applied to the design of an intensive 2-credit hour, large enrollment, online course for PSTs across nine education programs, communicate designers' visions for the course, and examine how learners experienced it (Howard et al., 2012). The primary aim of this case will be to richly describe the context and the design process along with its challenges and designers' experiences with the process. Additionally, this case will detail the resulting product and reflections on its implementation and potential for revision. In this case, we will first explore the use of the PEF to guide the design process for an online course to prepare PSTs for online teaching. As part of evaluating and reflecting on the course, we will also examine participants' experiences and perceptions of the resulting product: the course and its modules (Howard et al., 2012; Langub \& Lokey-Vega, 2017). Aligning with recent work on learners' experiences in online environments, our overarching questions focused on learners' (1) satisfaction with the overall design, (2) learning experiences in the course and PEF phases, and (3) perceptions of their preparedness for virtual student teaching (Ritzhaupt et al., 2020).

\section{Design Case}

\section{Context}

Participants in this design case were PSTs in a large teacher education program at a state university in the Northeastern United States. The PSTs had completed all program requirements prior to their final student teaching placement. Given the anticipated number of virtual field placements and that approximately half the PSTs had no prior course focused solely on technology integration, this ad hoc, 2-credit hour, pre-student teaching course was created and required for all education majors who would student teach in Fall 2020. The course was offered as an online, mostly asynchronous course. The only synchronous requirements were a one-hour class meeting and two small group meetings. The synchronous class meeting occurred on the eighth day of the course. Per request of the college administration, an instructor facilitated a synchronous training for the newly adopted, virtual, student teaching supervision platform. The synchronous group meetings, occurring in Modules 2 and 4, were incorporated in the course to provide opportunities for PSTs to practice facilitating synchronous discussions and to promote social and cognitive presence in the course.

Three course sections were created on the institution's learning management system (LMS) - one for each school represented (i.e., School of Education, School of Arts and Sciences, School of Professional Studies). Table 1 provides a breakdown of the programs for the 237 students enrolled in the course. The course ran for 10 days at the beginning of the Fall 2020 semester. The course ended on a Friday, and PSTs began their placements the following Monday.

\section{Role of the Researchers}

It is common for design case authors to have served as the designers and even the instructors of the course (Langub \& Lokey-Vega, 2017; Svihla \& Boling, 2020). While the design case may require these multiple roles, it can strengthen a case narrative as course designers have insider knowledge of the problem, how it was addressed in the course design, and the decisions made during the process 
(Donaldson et al., 2020; Hall \& Lei, 2020). For this design case, the first and second authors served as the designers and instructors of the course. As course instructors, the authors were able to monitor the fidelity of course implementation, experience barriers or challenges that arose, make just-in-time adjustments, and ensure that formative and summative evaluation measures were deployed. The first author was the lead designer and instructor of record. In this role, the designer-author managed the project and led the team in framing the course, developing resources, and planning the evaluations. In addition to discussing foundational design elements through the process, the second designer-author, an assessment specialist, led the development and instruction of the assessment module.

\section{Data}

As Langub and Lokey-Vega (2017) highlighted, data in design cases can be somewhat unique as "thick description with triangulating data points and audit trails serve to remind the designer and inform the reader of the design decisions, events, and outcomes" (p. 323). Data in this design case, therefore, included descriptions of the designer-authors' decisions, illustrations of course design artifacts, and reflections on the process and products (Beriswill, 2014; Donaldson et al., 2020; Howard et al., 2012). As part of the evaluation phase for this design case, PSTs completed a post-course questionnaire to detail their learning experiences and share their perceptions of the course. Using a Likert scale (1 = Strongly Disagree, 5 = Strongly Agree), participants rated the degree to which each part of the module (i.e., Actively Explore, Reflect and Discuss, Explain Concepts, and Apply Learning) helped them achieve the course learning goals; each Likert-scale question provided participants the option to not answer. Following these closed responses, the last four questions prompted student (1) explanations of their previous Likert-scale responses and what they would (2) keep the same, (3) change, or (4) remove from the course.

Once PSTs completed their student teaching, they also responded to questionnaire prompts on how they believed the course experience and topics prepared them for virtual student teaching. Furthermore, this post-student teaching questionnaire asked participants to reflect on what they would add to the course to better prepare PSTs for what they experienced in their virtual placements. Per the approved IRB protocol, PSTs were informed of the study at the beginning of the post-student teaching questionnaire and were invited to participate. There was no incentive to participate, and participants were able to withdraw from the study at any time. Of the 237 PSTs who completed the course in Fall 2020, 139 consented to participate in this study. Of those who consented to participate, there were 109 responses to the post-course questionnaire and 139 responses to the post-student teaching questionnaire.

\section{Framework for Course Design}

Beginning the course design process with a front-end analysis, we met with college administrators about their vision for the course and analyzed the Spring 2020 exit survey data. The Spring 2020 exit survey was completed by PSTs who had just completed student teaching, their mentor teachers, and the placement supervisors. PSTs' responses indicated that the current educational technology course and experiences throughout the program were perceived as beneficial and adequate for face-to-face classrooms. The survey, however, indicated that preparation for online teaching and learning had not been adequate within the programs. A new course, therefore, could build on the technology integration foundation with an emphasis on online environments.

When responding on the exit survey about PSTs' virtual teaching abilities, mentor teachers indicated that some PSTs were somewhat prepared for technological aspects of remote learning with many mentor teachers considering PSTs as partners in the new virtual teaching landscape. Reverse mentorship opportunities were even noted as PSTs helped mentor teachers with the shift to online instruction. However, PSTs needed time to learn specific technologies that had been adopted by the district, and the implementation of blended and virtual pedagogies was not always at the level that mentor teachers expected. Specific areas for improvement included managing synchronous virtual sessions and integrating authentic assessments in fully online classes. Lastly, it was observed that PSTs needed a greater repertoire of strategies for increasing student interaction and engagement online.

The sole educational technology course structure in teacher education programs has significantly impacted PSTs' development (Wilson et al., 2020) and has indeed shown promising results for programs included in this design case. However, our front-end analysis revealed gaps in PSTs' development of competencies for teaching K-12 online. In their review of blended and online K-12 instruction, Pulham and Graham (2018) categorized the most frequently referenced K-12 online teaching competencies which included classroom management, operating an LMS, assessment practices, and student-centered learning. These four competencies were all identified as areas for growth in our front-end analysis, further indicating the need for a course dedicated specifically to virtual teaching competencies.

The ISTE Educator Standards have been the primary guiding document for most educational technology coursework in our programs. While the ISTE standards 
have been valuable for prior course designs, they were not written specifically for virtual teaching. Therefore, these standards did not address online teaching competencies (Pulham \& Graham, 2018) with the desired precision and depth. Shifting attention to the International Association for K-12 Online Learning's work in this area, we anticipated the NSQOT (Virtual Learning Leadership Alliance \& Quality Matters, 2019) would be a more suitable framework for the course design. Given the extensiveness of the standards and the short duration of the course, we determined it would not be possible to equally address each one; however, the flexibility of the standards can be observed in this design case as each of the eight NSQOT categories were integrated in different ways and to varying degrees based on the needs of our audience. For example, several NSQOT categories guided the design of standalone modules (i.e., Community Building, Learner Engagement, Digital Citizenship, Diverse Instruction, and Assessment), while other NSQOT categories such as Instructional Design and Professional Responsibilities were distributed across all modules in the form of the virtual lesson plan course project.

\section{Presence + Experience Framework}

The Presence + Experience Framework (PEF) guided the design process in this course (Dunlap et al., 2016). Originally developed in teacher education as a model for designing online courses, this framework was a perfect fit for our context. Additionally, the PEF's philosophical roots of sociocultural and experiential learning fit with the intended nature of the design product. Lastly, the PEF's flexibility in terms of time, sequencing, and required technologies for implementation were critical affordances for designing a 10-day course.

In Fig. 1, the CoI Framework is depicted by the three elements in the outer parts of the circles: teaching presence, social presence, and cognitive presence (Garrison et al., 2000). Teaching presence is the facilitation of the $\mathrm{CoI}$ elements as a means of achieving the course learning outcomes. It can be observed in the how the instructor organizes the course, facilitates discussions, and provides direct instruction (Shea et al., 2010). As indicated by intersections of the three circles in Fig. 1, an instructor or designer can support teaching presence in the ways they select content or create course climate. Shea and Bidjerano (2008) defined social presence as "the capacity of participants to establish satisfying relationships and levels of interaction necessary to engage in discourse that is foundational to learning" (p. 343). Setting the instructional climate is essential for attending to social presence along with supporting discourse. Many methods for promoting social presence have been explored, from creating

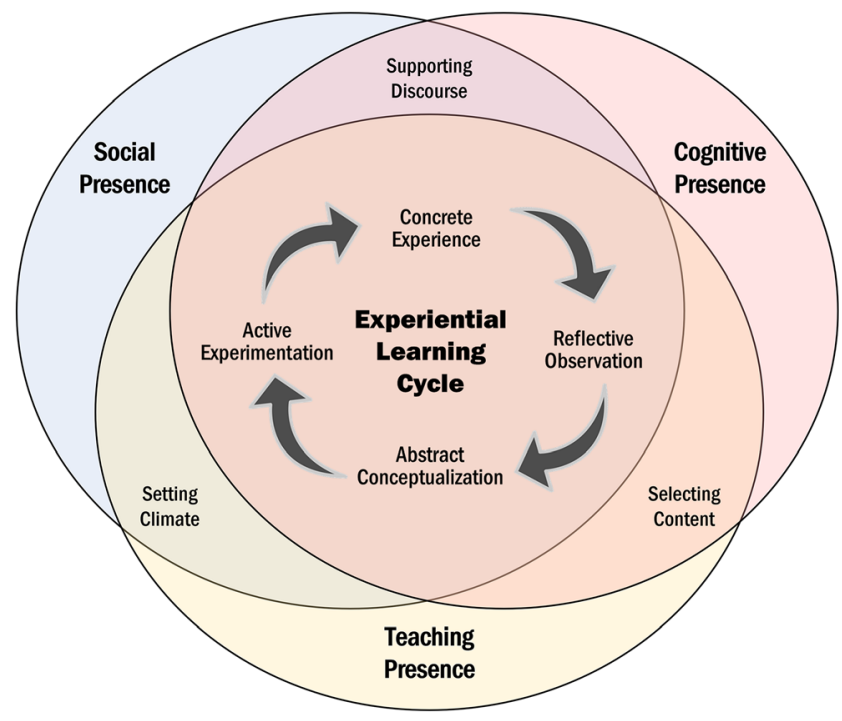

Fig. 1 Experiential Learning Cycle within the Community of Inquiry Note: Adapted from Dunlap, J. C., Verma, G., \& Johnson, H. L. (2016). Presence+experience: A framework for the purposeful design of presence in online courses. TechTrends, 60, 145-151. https://doi.org/10. 1007/s11528-016-0029-4

conversation spaces for students to socialize (Correia, 2020) to designing purposeful prompts for guiding reflective discourse (Johnson et al., 2019). Finally, cognitive presence is learners' ability to construct meaning in a learning environment and is viewed as fundamental to achieving course outcomes (Garrison et al., 2000). Selecting content and supporting discourse related to that content, therefore, are essential to ensuring that learners are engaging cognitively, constructing meaning, and pursuing course learning outcomes.

While numerous studies have empirically investigated the CoI constructs, claims, and teaching strategies (Castellanos-Reyes, 2020), the PEF uniquely provides a systematic, instructional design process for incorporating CoI elements (Dunlap et al., 2016). The essential CoI elements and supporting interactions are integrated in the design through learners' engagement in Kolb's experiential learning cycle. The experiential cycle, situated in the center of the CoI in Fig. 1, frames each unit of instruction. Whether these instructional units are single day lessons or weeklong modules, learners engage in the four experiential phases: (1) concrete experience, (2) reflective observation, (3) abstract conceptualization, and (4) active experimentation (Kolb, 1984). As course designers develop instruction for this experiential cycle, they attend to the $\mathrm{CoI}$ intersections and strategies for supporting discourse, setting climate, and selecting content. In summary, course designers applying the PEF will systematically consider CoI strategies when designing instructional units that engage learners as "activists, reflectors, theorists, and pragmatists" (Morgan, 2008, p. 35). 
In Fig. 2, the experiential learning cycle in the center of the PEF has been modified to illustrate how these phases of learning were communicated to students. When they proposed the PEF, Dunlap et al. (2016) communicated the experiential phases with the addition of the terms experiencing, examining, explaining, and applying. These terms remain in the center of Fig. 2 to demonstrate the connection to the PEF, however, underlined phrases have been added beneath Dunlap et al.'s terms. In this design case, the phrases actively explore, reflect and discuss, explain concepts, and apply learning represented the experiential phases in the course. Except for the course introduction, every module contained a folder that was titled with these phrases. While the learning in these folders aligned with the associated experiential cycle, the terminology was adapted to better communicate what students should expect when engaging the materials in that part of the module. Throughout the remainder of this design case, the experiential phases will be referred to by these underlined phrases (i.e., actively explore, reflect and discuss, explain concepts, and apply learning). These terms can be mapped from Fig. 2 to the corresponding experiential cycles in Fig. 1 and the PEF terms applied by Dunlap et al. (2016).

\section{Applying the Presence + Experience Framework}

\section{Actively Explore}

At the start of each module, PSTs were encouraged to spend approximately 75 min actively exploring the content and digital resources that related to the module topic as a way to gain experience with the content. For

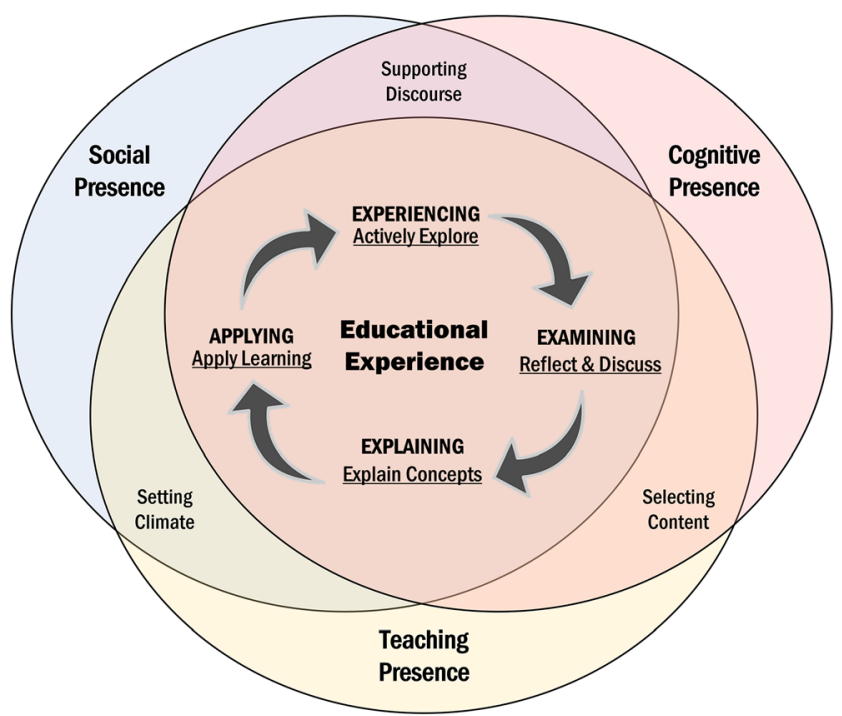

Fig. 2 Adapted Presence + Experience Framework Note: Adapted from Dunlap, J. C., Verma, G., \& Johnson, H. L. (2016). Presence+experience: A framework for the purposeful design of presence in online courses. TechTrends, 60, 145-151. https://doi.org/10.1007/s11528-016-0029-4 this Experiencing phase, referred to in this design case as Actively Explore, Dunlap et al. (2016) emphasized the importance of selecting engaging and relevant content to increase both cognitive and teaching presence in a course. To support the relevancy of the content, we ensured that it aligned with the module's learning outcomes and explained how it could benefit PSTs both now and in their future teaching (Keller, 1987). Additionally, we incorporated a range of experiences and allowed learners to choose which resources to explore and the depth of their exploration. When high quality, relevant resources could not be readily found, we also modeled enthusiasm for the content by creating our own video and text-based resources (Shea et al., 2010).

As a glimpse of what an Actively Explore phase might involve, we will describe the activities in the Digital Pedagogy module. To begin, the folder opened with a brief overview of the resources students could engage with, explained why the resources had been selected, and introduced the learning outcomes. Four content sections were then displayed to encourage explorations of web-based technologies that could support communication with students and families, meet individual learner needs, or promote content understandings: Whiteboard.fi, Loom, Google Slides, and Vocaroo. Each began with a text-based introduction followed by either a video tutorial or linked resource to explore.

For example, the introduction for Loom situated the technology as beneficial for video feedback and modeling. Loom is a free, simple to use, video messaging tool that can record a screen, webcam, or both simultaneously. Loom videos are stored online and available to share with a link in seconds, thereby supporting timely and seamless online communication. Using the screencast feature of Loom, a teacher can model procedures in online environments or contextualize feedback on assessments (West et al., 2017).

The overview of Loom began by reminding PSTs that feedback and modeling occur in the face-to-face classroom through various means (e.g., circling the room, meeting with students, or offering varying degrees of support in small groups). In the online world, these supports are still necessary, but it can be challenging to model a solution or communicate specific, visual feedback asynchronously. After setting this pedagogical foundation, PSTs were presented with a video demonstration and link to Loom for practicing the tool. These explorations were then the foundation for the peer discussions which ensued in the next phase.

\section{Reflect and Discuss}

Setting a climate that fosters strong discussion is an essential CoI strategy and was intentionally integrated in the 
Examining phase: termed Reflect and Discuss in this design case (Johnson et al., 2019). Teaching presence was further incorporated through specific directions for each discussion, explicit expectations and prompts for each group to engage, support for using the discussion medium, and timely feedback to groups (Shea et al., 2010). Learning how to create and facilitate online discussions with a variety of platforms used in K-12 was a key course learning outcome (Virtual Learning Leadership Alliance \& Quality Matters, 2019). Therefore, each student served as the discussion facilitator for their group one time by creating the discussion on the assigned platform, sending the information to group members, and completing the facilitator summary.

The facilitator summaries were an adaptation made due to the large enrollment of this course. Instructors of smaller sections may actively facilitate ongoing discussions (Dorner \& Kumar, 2016), but the 50 groups in this course participating in six discussions over the span of 10 days made it unfeasible for the instructor to actively participate in the dialogue. Thus, a facilitator summary form was developed for each discussion. On this form, the facilitator documented who participated in the discussion, summarized the conversation, and detailed concerns or questions that group members had about the course. Instructors could review these forms between discussions and respond to groups' questions and concerns. While this was not a substitute for the benefits of having an instructor's participation in a discussion, facilitators were expected to think about how they would summarize discussions, encourage the engagement of their peers, and assess participation (Shea et al., 2010).

To encourage social presence throughout the 10 days, students were placed in a small group (i.e., most groups were five students) for the duration of the course. The PSTs, who would be student teaching at the conclusion of the course, had already been assigned to supervising teachers. Supervising teachers work with PSTs during student teaching and are assigned to students based on the region where PSTs will complete the field experience. Therefore, the small groups were composed of PSTs who shared a supervising teacher; this strategy ensured group members were of the same program and were student teaching in proximate districts. Creating groups in this manner was intended support more robust discussions and peer support as PSTs would be creating lessons specific to their programs, offering feedback to peers, and considering the local context for their assignments. It was also likely to build stronger collaborations upon relationships that had been formed within prior courses. Keeping group membership constant, a pedagogical decision to support community building in this fast-paced course, was logistically advantageous as groups would be setting up and facilitating a mix of synchronous and asynchronous meetings across varying platforms (e.g., Webconferencing systems, Flipgrid, Vialogue, and Blackboard).

The Reflect and Discuss phase was designed to connect to the preceding Actively Explore phase. During the Learner Engagement module, PSTs actively explored Bitmoji classrooms through a reading that highlighted teachers' varied experiences and examples of practice (Gewertz, 2020). They also read NSQOT's Learner Engagement standards (Virtual Learning Leadership Alliance \& Quality Matters, 2019). For their discussion, the facilitator created a Flipgrid thread for the group with a prompt focused on debating how Bitmoji classrooms may or may not achieve the NSQOT standards. PSTs were also challenged to defend their position on whether Bitmoji classrooms should be used with K-12 learners. Facilitators set and assessed the participation requirements for their group. By the due date, facilitators then submitted a report using Google Forms.

\section{Explain Concepts}

The emphasis of the Abstract Conceptualization phase, referred to in this design case as Explain Concepts, is for learners to grasp theories underlying their experiences. Proficiency with these theories would enable learners to explain prior work in the module and abstract essential elements from the theories, which they could apply in upcoming work or real-world practice (Dunlap et al., 2016). Outlined in Table 2, the primary frameworks shared with learners in this course were Community of Inquiry (Garrison \& Arbaugh, 2007), Personalized Learning (Graham et al., 2019), and Universal Design for Learning (UDL; Center for Applied Technology, n. d.). As these frameworks were introduced, there were explicit attempts to connect them to the first two phases and expectations in the final phase for learners to indicate how they were applied.

Strengthening teaching presence in the course, the Explain Concepts phase contained the highest concentration of instructor-created videos. For example, the Diverse Instruction Module had four instructor-created videos (average length of $8 \mathrm{~min}, 20 \mathrm{~s}$ ), which explained how UDL connected to online teaching and learning. These topics were (1) an overview of UDL in online settings, (2) UDL for promoting self-regulated online learning, (3) UDL connections to best practices for teaching English Language Leaners online, and (4) selecting media to support UDL practices (Ableser et al., 2018; Carr-Chellman, 2016). Although not professionally produced, principles of multimedia production were followed to support cognitive engagement with this content (Mayer \& Moreno, 
2003). Quizzes were deployed in each module's Explain Concepts phase to promote learners' cognitive presence and engagement with the instruction. Approximately 10 items long and set for multiple attempts, learners could monitor their own progress toward the goal of explaining the module's concepts.

\section{Apply Learning}

Lastly, learners in this design case were engaged in active experimentation of concepts during the Apply Learning phase of instruction. Although each module had unique applications of knowledge closely connected to the module's learning outcomes, the apply learning phase connected modules together within a real-world, complex task (Merrill, 2012). Dunlap et al., (2016) posited that connecting applications of learning to field experiences can help foster the intersections of social, cognitive, and instructor presence. During the course introduction, therefore, learners were asked to identify a lesson they would create for a virtual classroom. It was highly recommended that PSTs identify a face-to-face lesson plan they had already created in a previous methods course. The assumption was that a previously created lesson would have already been vetted and given feedback by an expert in the content area. Given the large range of programs in the course, we did not presume to be subject matter experts in most of these disciplines. Secondly, we assumed that a previously created lesson plan would have a strong foundation (i.e., strongly written and aligned learning outcomes, assessment plans, and content standards) from which PSTs could build upon and adapt for an online environment. Since PSTs likely had several preexisting plans from which to choose, we also recommended the plan should match the grade level of their final student teaching placement.

Along with identifying their lesson plan, PSTs confirmed the LMS used by the mentor teacher in their upcoming field placement. In the Learner Engagement module's Apply Learning phase, PSTs then setup an account and classroom on the identified LMS and enrolled each of their group members as students. As an overarching framework for their lesson design, PSTs applied a systematic approach to designing their lesson and developing or selecting materials (Carr-Chellman, 2016). To help orient PSTs to this instructional design framework, we explicitly demonstrated how each Apply Learning assignment would fit into the virtual lesson they were designing.

For example, the fifth step in Carr-Chellman's (2016) framework is for teachers to "analyze and select available texts" (2016, p. 144). After being introduced to critical copyright concerns and the concept of open educational resources (OER) in the initial phases of the Digital
Citizenship module (Kimmons, 2020), PSTs were tasked with identifying OER that could be incorporated into their virtual lesson. As support for this assignment, we created a five-minute video on ways to integrate OER in online courses and shared eight favorite OER databases with brief text-based descriptions of what PSTs could expect to find on these websites. Across the eight OER databases highlighted, we included at least one relevant website for each program in the course. PSTs also had access to an externally compiled list of OER websites and search engines to help them find high quality OER of varying modalities (Liao, 2020).

As PSTs designed and developed their virtual lessons, they were encouraged to share and review their progress with their peers. In the Reflect and Discuss phase of the Digital Pedagogy module, groups were assigned to synchronously meet and share their virtual plans. Peers provided feedback and addressed technical or pedagogical issues faced by the group. Having group members join peers' virtual classes was intended to also generate ideas through observing various lesson designs in progress. The authentic nature of the task was intended to foster motivation, promote learning of transferrable skills, and provide PSTs with an effective virtual plan for their upcoming field placements (Keller, 1987; Merrill, 2012).

\section{Findings}

The PEF was a useful guide for our instructional design process, and as the lead instructors in the course, two designer-authors closely observed its implementation. During the course, these instructors met frequently to discuss observations and document necessary revisions for future iterations. In this section, we will share what was learned about designing with the PEF from our experiences, observations of the course's implementation, and reflections on the design process. Although future research can examine the significance of student learning, we will present themes and illustrative quotes from participants' questionnaire responses on the post-course survey and the questionnaire completed after their student teaching placements as evidence of the potential efficacy of this design. These data served as evaluative measures of learners' experiences with the design and satisfaction with preparation for virtual student teaching.

\section{Composing the Cycle with Complementary Phases}

Working from Dunlap et al.'s (2016) recommendation to first define the course's instructional units and then involve learners in all phases of the experiential learning cycle while integrating CoI strategies, we first defined 
units of instruction with the NSQOT standards. Next, we designed opportunities in each module for learners to engage in exploration, reflection, abstraction, and application. When learners opened a module, they were greeted with an introduction, NSQOT-based student learning outcome(s), and four folders marked Actively Explore, Reflect and Discuss, Explain Concepts, and Apply Learning. Although all phases were designed to foster distinct engagement with the content and peers (Dunlap et al., 2016; Kolb, 1984), they were also intended to complement one another. Complementarity, however, was difficult to achieve as it involved careful planning and additional resources to clearly communicate the purpose of each phase of instruction at the outset of the course. It also required reiterating the connection between resources and activities in the phases while avoiding potential redundancy.

One indicator of achieving a complementary design would be that learners perceived each PEF phase as distinctly and holistically beneficial to their learning. Asked to indicate on a 5-point Likert scale their level of agreement that a phase of instruction influenced their learning, participants perceived all phases to be beneficial (Actively Explore $M=4.10$; Reflect and Discuss $M=4.00$; Explain Concepts $M=4.13$; Apply Learning $M=$ 4.24). When explaining these Likert scale responses, 28 of $109(26 \%)$ participants replied with a breakdown of how each PEF phase contributed to their learning. For instance, Participant 5 (P5) wrote:

Actively Explore gave me an opportunity to push myself and learn more about the topic in the module. This helped me know more information for the rest of the module. Reflect and Discuss allowed me to connect with peers to check in and see if we are all up to date and finishing our assignments and doing them correctly. Explain Concepts influenced learning by giving more information about the topic. This helped us have knowledge for our student teaching and about technology. Apply Learning allowed us to create our own products and practice so we have experience with different tools.

Of the 28 participants who detailed the phases of the PEF in their responses, 21 described the Actively Explore phase as providing some form of introduction or background knowledge, Reflect and Discuss as prompting peer interaction, Explain Concepts as offering additional depth on the topic, and Apply Learning as gaining experience with technology by developing resources.

While unique in emphasis, participants also viewed phases as related to one another $(n=19)$ and as scaffolds for the final application of learning $(n=14)$. The following quotes illustrate perspectives on how phases related to each other:
Each section of the modules had different information that, together, helped me achieve the course's learning goals. With the combination of all four sections, I felt confident in my ability to complete the work, but did not feel so overwhelmed when looking at each module since it was nicely broken up into smaller parts (P55).

I liked how each module scaffolded learning, so by the end of each module I was equipped with the right amount of knowledge and confidence to apply my learning (P71).

Participants perceived the phases as distinct yet relevant; P55 wrote of being able to combine the sections and break the module into smaller parts. The phases' connection was also viewed as building toward a culminating objective; P71 described it as "scaffolded learning" and being "equipped with the right amount of knowledge and confidence to apply my learning." While the PEF affords designers the flexibility to organize the phases in any order, we designed each module to close with application. Thus, participants saw the first three phases as building their knowledge and confidence for application in their design tasks.

\section{Creating a "Great Space" to Explore}

Given that PSTs benefit from exploring novel technologies (Lei, 2009) and having course space to gain new experiences (Hall, 2018; Hall et al., 2020), the Actively Explore phase was a critical design element. In terms of the CoI, Dunlap et al. (2016) highlighted the importance of selecting content that fosters both cognitive and teaching presence during the Actively Explore phase. When selecting content for exploration, we identified or created relevant activities and media that afforded experience with varying digital tools and strategies for online teaching. To promote cognitive presence, PSTs explored concepts through games, experimented with technologies, and discussed explorations with peers. Although the activities and prompts for exploration were straightforward to develop, selecting digital tools that were contextually relevant and open for exploration proved to be a challenge.

Regarded as a "great space for resources" by P59 and a place to "experience technology and try it out first hand" by P32, many participants found the space valuable, in P81's words, for "showing [them] all of the tools for... teaching online." There were positive indicators of satisfaction with the content selection, albeit not all tools for the trade were introduced. This was a prime difficulty when designing an intensive course for nine different majors. P56 highlighted this tension whey they wrote that future iterations of the course should include "department specialized content...the unpacking the standard 
assignment a professor within each department could have provided an example to use." Although experts in technology integration, we were not subject matter experts in all the content areas. We attempted to resolve this gap in knowledge by reaching out to experts in various content areas, but the short time frame for designing the course limited responses and our capacity for incorporating feedback within this iteration.

Amidst the appreciation for the range of tools explored, there was a desire for a course tailored to specific placements. When recommending improvements for the course following student teaching, P61 shared, "Try to gain an idea of what most of the schools are using and teach the students those platforms." Aligning with this statement, P38 wrote, "I would suggest focusing on the main applications more and ensuring everyone is super familiar with them." Selecting content for exploration and identifying which digital platforms would be most widely used in the PSTs' teaching placements was a significant challenge, as the placements spanned the entire state. Furthermore, the state's nascent integration of online teaching was a barrier to identifying tools that would be used in all schools.

Hence, some activities were open to exploring a set of tools of a given type (e.g., LMSs, web conferencing platforms, video editors), and students were invited to practice the tool adopted by their placement school. However, frustration occurred when certain features (e.g., creating assignments, breakout rooms, larger file sizes) were not supported by a platform's open version. For example, the college's Microsoft student accounts granted limited access to what PSTs could develop on Teams, and they had not yet been given access to their placement school's Microsoft Teams accounts. Knowing their placement schools were using Microsoft Teams, however, 24 PSTs attempted to setup their virtual lessons on the platform. Frustrated they could not explore Teams in more depth, P99 wrote, "It is important for students to have a teacher account for Microsoft Teams to get the full understanding of how it is set up." While PSTs experienced the course as a great place to explore new technologies, PSTs expressed a desire for additional content specialized for their major and technology explorations tailored to their student teaching placements.

\section{Community and Presence: Working "Through this Experience Together"}

PEF-designed courses should engage teachers and students in "community-oriented, knowledge building interactions" (Dunlap et al., 2016, p. 146), ergo it was essential to explore PSTs' sense of community in this design case. The Reflect and Discuss phase was intentionally designed to facilitate peer interactions and community building. For example, the 237 students were purposefully placed in small groups with peers in their program who shared a supervising teacher for their field placements. To support discourse and foster a climate for learning, each of the six discussions had a focused prompt (Johnson et al., 2019), clear parameters, netiquette guidelines, instructions for participation, and support for using the assigned medium effectively (Shea et al., 2010).

Forty PSTs explicitly referenced the Reflect and Discuss portion of the course in the exit survey, and 37 of these comments indicated how this phase benefitted their learning experience. Of the three participants who did not find it beneficial, only one provided a specific comment, and the feedback revealed that their dissatisfaction stemmed from an absentee group member. Most commonly, however, PSTs $(n=16)$ responded that discussing content with peers supported their learning by sharing ideas and gaining new perspective. Illustrative of this theme, P35 wrote, "Reflect and discuss strongly helped me achieve the learning goals because it allowed me to discuss with my group members, share my ideas and hear from others. I enjoy hearing about others ideas because it allows me to see other points of view." Notably, P35 viewed the content of the discussion as a knowledge building interaction that was consistent with course goals and strengthened by the contributions of the group.

Aside from the content discussion, PSTs $(n=10)$ perceived the Reflect and Discuss phase as beneficial for supporting each other in the course. P34 bridges these themes of content discussion and peer support when they wrote, "I thought the Reflect and Discuss section was extremely beneficial because we got to work in groups and see what other group members were thinking about a certain discussion. I liked having a group to talk to so that we could all help each other throughout the course." For P34 and others, there was value both in the discussion of course content and in the group talk that could foster success in the course. Similarly, P142 responded, "The reflect and discuss portion was valuable because I was able to communicate with my peers on their opinions and we worked through this experience together." A specific way that PSTs mentioned helping each other work through the experience was with practicing the technologies for facilitating the discussions. The Reflect and Discuss phase, therefore, may have also supported active experimentation with online communication tools.

\section{Adapting Phases for Increased Practice}

Since the course covered seven modules in 10 days, it became overwhelming for some learners to engage all 
phases. In the course feedback, learners expressed these sentiments by asking to extend the course timeline or reduce the numbers of modules and mentioning they would have learned more if there were less content. P83 wrote, "This was an effective course, just felt it was very condensed"; P83 proceeded to suggest removing the Digital Citizenship module. Similarly, P17 wrote, "The course was jam packed with so much work that instead of learning and using the resources, I felt we were just rushing to meet deadlines and get work done."

The PEF's developers advised designers to carefully consider the audience and instructional unit when determining how much to emphasize each phase of Kolb's cycle (Dunlap et al., 2016). Not all phases of the cycle need to be equally emphasized, nor do modules need to be identical in their emphases. Reflecting on our application of the PEF, this is a design affordance that was not fully leveraged. Module paths were typically linear, from Actively Explore to Apply Learning, and designed for learners to spend approximately equal amounts of time in each phase. Differentiating between phases and modules may improve future iterations by focusing even more on phases that PSTs perceived as most useful.

Participants' responses on the exit survey indicated that the application assignments in the course were most beneficial to their placements $(M=4.24)$ and needed to be expanded in the course. Sixty-five participants strongly agreed that Apply Learning activities benefitted their learning, while other phases received either 51 or 50 strongly agree responses. Regarding Apply Learning, P145 wrote, "I loved this folder. I can read about the different things to do in a classroom, but testing myself on using the technology and becoming familiar with it will serve as a huge advantage in the field." Perceived as the "most effective part of this course" by P105, participants viewed the practice of tools and skills in the Apply Learning phase as immediately germane to their teaching.

\section{Discussion}

Applying the PEF to this intensive, large enrollment, online course resulted in a design that PSTs viewed as beneficial in its distinct phases and their relationship to the whole. PSTs perceived all the CoI integrated experiential cycles to have positively influenced their learning, but there is room for improvement in the next iteration. One participant noted that the Explain Concepts and Actively Explore phases overlapped too much, and another participant felt the Explain Concepts phase was simply busy work. Instructor created videos on frameworks that inform online teaching, intended to foster teaching presence, comprised much of the Explain Concepts phase. If these abstract concepts are not comprehended or connected to the other modules, the content is likely to feel superfluous. To assist with making these connections, the next course iteration will include additional, context-specific examples and non-examples of the concepts being demonstrated to learners (Merrill, 2012).

Across all nine programs, participants most frequently suggested that the Apply Learning phase be more prioritized. The design problem for future iterations then becomes how to expand the Apply Learning phase when some learners also perceived the course to be dense and overwhelming in the short timeframe. The solution may be to differentiate the emphases placed on phases in the experiential cycle and how much instructional time is devoted to each. Acknowledging the potential for more flexible application of the PEF, the next iteration will include more application and practice. The first actionable step will be to remove the digital citizenship module and redistribute the content as supplementary resources for related assignments within other modules. After reflecting on the pacing of the course, the designer-instructors determined that covering six modules and a course introduction over a 10-day period left little time for students to integrate what they were learning into preparations for their teaching placements. In addition to this intensive course, some students had begun meeting with their supervising teachers and attending professional development workshops at their placement schools. Distributing the digital citizenship resources throughout the other modules is intended to offer students additional practice with curating openly licensed materials for the various parts of their virtual lessons. Additionally, to further improve the course pacing and support students' learning in the next course iteration, one teaching day will be added to the course schedule.

With this margin, additional opportunities for practice and application can be incorporated. For example, the virtual lesson plan assignment can include the creation of a screencast video that provides an overview of the lesson for a K-12 audience. Secondly, practicing with HyperDocs, "interactive, digital teaching and learning materials created, disseminated, and remixed by educators" (Carpenter et al., 2020, pg. 2), can complement students' choice board development by demonstrating the broad, pedagogical applications of these skills. HyperDocs have been widely used in online K-12 settings and are a flexible way to integrate technology without being 
constrained to a single digital tool (Carpenter et al., 2020), but initial research indicates discrepancies in teachers' ability to design, use, and evaluate the quality of HyperDocs. This knowledge gap and the high likelihood that PSTs will encounter HyperDocs during a virtual teaching placement make this a viable area for additional application. As these adaptations to the Apply Learning phase increase the expectation of time learners will engage these resources, all other phases will be carefully reviewed for materials that may have yielded low engagement or could have been redundant. The goal in these adaptations, in line with Dunlap et al.'s recommendations (2016), is to strategically consider our audience when designing the instruction. In this design case, that strategic response may be an increased focus on practicing meaningful and transferrable skills.

\section{Implications for Practice}

The COVID-19 pandemic may have highlighted teachers' lack of experience in online or blended settings (Trust \& Whalen, 2020), but infusing blended and online competencies in teacher education has long been recommended (Archambault \& Kennedy, 2014; Hall, 2018; Kennedy \& Archambault, 2012). As the immediate need for K-12 emergency remote teaching subsides, teacher education programs should consider developing PSTs' online pedagogies in the context of blended teaching and learning. Competencies such as "flexibility and personalization, online discussion facilitation, community development, and mastery-based learning" (Pulham \& Graham, 2018, p. 421) can prepare PSTs for online or blended settings. Explicitly modeling quality online teaching (i.e., NSQOT) in PST coursework may be an initial step. Similar to this design case, programs could also develop coursework that focuses on addressing online or blended teaching standards. The PEF may then help teacher educators model quality online teaching through their course design as they prepare PSTs for the varied situations, formats, and contexts they are likely to encounter (Trust \& Whalen, 2020).

Although this case emerged as a response to a COVID-19 design problem, the potential design applications for the PEF extend beyond the pandemic. Higher education institutions have expanded online courses and creatively adapted pathways to degrees, yet designing quality engaging content, and course interactions have been persistent barriers (Siemens et al., 2015). This design case illustrated the PEF's capacity to inform an ad hoc course offering and create an online space that fostered interactions with content and peers; however, future designers may want to incorporate alternative CoI strategies to facilitate these interactions. Although the experiential cycle is a systematic and prescriptive means to incorporate the CoI, there is still room for interpretations of how, when, and to what degree the CoI strategies are employed. Finally, novice instructional designers may benefit from more explicit guidelines for integrating CoI strategies (Branch \& Gustafson, 2002).

\section{Implications for Research}

Previous research demonstrated the PEF's potential for informing the design of standalone, online learning experiences (Johnson et al., 2019) and semester-long online courses (Dunlap et al., 2016) in teacher education. This design case details the process for designing an intensive, large enrollment, online course with the PEF and student perceptions of the resulting product. Initial research suggests the PEF can effectively inform the design of varying online environments; therefore, it may be worthwhile to further examine its impact. Future research should investigate PEF-designed courses beyond teacher education and explore the PEF's application to designing blended and hybrid courses.

\section{Conclusion}

This design case detailed the process and experiences of designer-instructors who developed an online course for preparing PSTs to teach online. The course design, based on the PEF (Dunlap et al., 2016), sought to promote learning by engaging learners in cycles of exploration, reflection, abstraction, and application while attending to social, teaching, and cognitive presence in the online environment. While the context-specific design decisions and lessons learned may not be generalizable beyond the bounds of this case, our approach to designing and addressing the problem may serve to inform future research and inspire designers as they adapt knowledge from this case for their context (Svihla \& Boling, 2020). Furthermore, the promising evaluation of the resulting product affirms the PEF's potential as an instructional model for online courses. Future research should empirically investigate learning outcomes in PEF designed interventions, explore variations to the sequencing and emphases of the cycles, and apply the PEF to designing courses outside of teacher education. 


\section{Appendix 1}

Table 1 Participant Overview

\begin{tabular}{llll}
\hline Section & School & Programs & Students \\
\hline 1 & School of & Inclusive Childhood Education & 110 \\
& Education & Childhood/Early Childhood Education & \\
2 & School of & Physical Education & 99 \\
& Professional & Health Education & \\
& Studies & Adolescent Education (Math, English, World Languages, & 28 \\
& School of Arts & Science, Teaching English as a Second Language) & \\
\hline
\end{tabular}

\section{Appendix 2}

Table 2 Course Design Overview

\begin{tabular}{|c|c|c|c|c|}
\hline Module & Student Learning Outcomes & Topic & Assignments & Timeline \\
\hline $\begin{array}{l}\text { 1. Course } \\
\text { Introduct- } \\
\text { ion }\end{array}$ & $\begin{array}{l}\text { Demonstrate presence in the online course, comprehension of } \\
\text { course expectations, and ability to navigate the LMS. }\end{array}$ & $\begin{array}{l}\text { - Orientation to } \\
\text { course structure } \\
\text { - Instructor } \\
\text { introductions } \\
\text { - Overview of K-12 } \\
\text { online teaching } \\
\text { and learning }\end{array}$ & $\begin{array}{l}\text { - Syllabus check-in } \\
\text { - Teaching with technology } \\
\text { pre-assessments } \\
\text { - Identify lesson for online } \\
\text { development and LMS used by } \\
\text { placement teacher }\end{array}$ & Day 1 \\
\hline $\begin{array}{l}\text { Commu- } \\
\text { nity } \\
\text { Building }\end{array}$ & $\begin{array}{l}\text { Describe methods for fostering active learning, collaboration, } \\
\text { and learner interactions in online environments. }\end{array}$ & $\begin{array}{l}\text { - Community of } \\
\text { Inquiry } \\
\text { - Setting community } \\
\text { expectations } \\
\text { - Strategies for } \\
\text { synchronous peer } \\
\text { interactions } \\
\text { - Facilitating } \\
\text { asynchronous } \\
\text { discussions }\end{array}$ & $\begin{array}{l}\text { - Group meeting - synchronous dis- } \\
\text { cussion of netiquette and inclusive } \\
\text { community expectations } \\
\text { - Community of Inquiry quiz } \\
\text { - Create teacher introduction video }\end{array}$ & $\begin{array}{l}\text { Days } \\
2-3\end{array}$ \\
\hline $\begin{array}{l}\text { 3. Learner } \\
\text { Engage- } \\
\text { ment }\end{array}$ & $\begin{array}{l}\text { Operate essential elements of a learning management system } \\
\text { and build an awareness of alternative content delivery } \\
\text { systems. }\end{array}$ & $\begin{array}{l}\text { - Personalized } \\
\text { learning } \\
\text { - NSQOT learner } \\
\text { engagement } \\
\text { standards } \\
\text { - LMS examples and } \\
\text { tutorials } \\
\text { - Developing lessons } \\
\text { in LMS }\end{array}$ & $\begin{array}{l}\text { - Group meeting - Flipgrid discussion } \\
\text { evaluating Bitmoji classrooms } \\
\text { - Personalizing instruction quiz } \\
\text { - Setup class shell in LMS }\end{array}$ & Day 4 \\
\hline $\begin{array}{l}\text { 4. Digital } \\
\text { Citizens- } \\
\text { hip }\end{array}$ & $\begin{array}{l}\text { Curate online, discipline-specific resources which comply } \\
\text { with copyright law, fair-use standards, and open licensing } \\
\text { attribution, while considering standards-based learning } \\
\text { goals and school-based regulations. }\end{array}$ & $\begin{array}{l}\text { - Copyright law } \\
\text { basics } \\
\text { - Open educational } \\
\text { resource } \\
\text { repositories }\end{array}$ & $\begin{array}{l}\text { - Group meeting - Synchronous re- } \\
\text { view of lesson ideas } \\
\text { - Copyright Quiz } \\
\text { - Identify OER for online lesson }\end{array}$ & Day 5 \\
\hline $\begin{array}{l}\text { 5. Digital } \\
\text { Pedagogy }\end{array}$ & $\begin{array}{l}\text { Apply various web-based technologies to communicate with } \\
\text { students and families, meet individual learner needs, and } \\
\text { promote content understandings. }\end{array}$ & $\begin{array}{l}\text { - Tools for } \\
\text { promoting online } \\
\text { interactions } \\
\text { - PICRAT model in } \\
\text { online courses }\end{array}$ & $\begin{array}{l}\text { - Group meeting - Vialogue discussion } \\
\text { of interview with K-12 online } \\
\text { teachers } \\
\text { - Digital pedagogy quiz } \\
\text { - Create instructional video }\end{array}$ & Day 6 \\
\hline $\begin{array}{l}\text { 6. } \\
\text { Assessm- } \\
\text { ent }\end{array}$ & $\begin{array}{l}\text { Purposefully review a variety of digital assessments and } \\
\text { explain how the results can inform future instruction. }\end{array}$ & $\begin{array}{l}\text { - Aligning } \\
\text { assessments with } \\
\text { learning outcomes } \\
\text { - GoReact training } \\
\text { - Digital assessment } \\
\text { tools }\end{array}$ & $\begin{array}{l}\text { - Assessment quiz } \\
\text { - Synchronous meeting with instructor } \\
\text { - GoReact training } \\
\text { - Group meeting - Assessment tool } \\
\text { showcase in GoReact }\end{array}$ & $\begin{array}{l}\text { Days } \\
7-8\end{array}$ \\
\hline
\end{tabular}


Table 2 (continued)

\begin{tabular}{|c|c|c|c|c|}
\hline Module & Student Learning Outcomes & Topic & Assignments & Timeline \\
\hline $\begin{array}{l}\text { 7. Diverse } \\
\text { Instructi- } \\
\text { on }\end{array}$ & $\begin{array}{l}\text { Create course materials that provide multiple means of action } \\
\text { and expression, representation, and engagement for diverse } \\
\text { populations. }\end{array}$ & $\begin{array}{l}\text { - Universal Design } \\
\text { for Learning } \\
\text { (UDL) founda- } \\
\text { tions } \\
\text { - No, low, and high } \\
\text { tech approaches to } \\
\text { UDL }\end{array}$ & $\begin{array}{l}\text { - Group meeting - Blackboard } \\
\text { threaded discussion of UDL strate- } \\
\text { gies } \\
\text { - UDL quiz } \\
\text { - Create virtual choice board }\end{array}$ & $\begin{array}{l}\text { Days } \\
\quad 9-10\end{array}$ \\
\hline
\end{tabular}

\section{Appendix C}

\section{Author Biographies}

Jacob Hall is an Associate Professor of Educational Technology in the Childhood/Early Childhood Education Department at SUNY Cortland. His research interests include the preparation of teachers for blended learning environments, technology integration to meet the needs of diverse learners, and the integration of robotics and computational thinking with young children.

Christine Widdall is an Associate Professor in the School of Education at the State University of New York, College at Cortland. Her research interests are in awareness and readiness for online instructional design strategies. Dr. Widdall's mantra as an educator is that students learn to think and do, not just recite and perform. She joined SUNY Cortland in 2000, where she hosted their first online course shortly after. She has continued teaching at Cortland for 21 years and remains focused on online education, educational assessment and effective educational change processes.

Jing Lei is a Full Professor in the Instructional Design, Development and Evaluation Department at Syracuse University. Her research interests include educational technology integration, meaningful technology use in schools, social-cultural and psychological impact of technology, teacher technology professional development, and international and comparative education.

\section{Declarations}

Conflict of interest The authors declare that they have no conflict of interest.

Ethics Approval All procedures performed in studies involving human participants were in accordance with the ethical standards of the institutional and/or national research committee and with the 1964 Helsinki Declaration and its later amendments or comparable ethical standards. The research in this study was approved by the SUNY Cortland Institutional Review Board (No. 202104).

Informed consent Informed consent was obtained from all individual participants included in the study.

\section{References}

Ableser, J., Hess, A. N., \& Moore, C. (2018). The Center for Excellence in teaching and learning quick notes series: Universal design for learning and technology. Oakland University.

Archambault, L. M., \& Kennedy, K. (2014). Teacher preparation for K12 online and blended learning. In R. Ferdig \& K. Kennedy (Eds.), Handbook of research on K-12 online and blended learning (pp. 225-244). ETC Press.

Barbour, M., \& Archambault, L. M. (2013). K-12 online distance education: Issues and frameworks. American Journal of Distance Education, 27, 1-3 http://www.tandfonline.com/doi/full/10.1080/ 08923647.2013 .759452

Beriswill, J. E. (2014). Design process of a goal-based scenario on computing fundamentals. TechTrends, 59(6), 15-20. https://doi.org/10. 1007/s11528-015-0899-x

Branch, R. M., \& Gustafson, K. L. (2002). Survey of instructional development models (fourth). ERIC Clearinghouse on Infromation \& Technology.

Carpenter, J. P., Trust, T., \& Green, T. D. (2020). Transformative instruction or old wine in new skins? Exploring how and why educators use HyperDocs. Computers and education, 157. https://doi.org/10. 1016/j.compedu.2020.103979

Carr-Chellman, A. A. (2016). Instructional design for teachers: Improving classroom practice (second). Routledge.

Castellanos-Reyes, D. (2020). 20 years of the community of inquiry framework. TechTrends, 64(4), 557-560. https://doi.org/10.1007/ s11528-020-00491-7

Center for Applied Technology. (n.d.). Overview of UDL, principles and information on assistive technology. http://www.cast.org/

Cirillo, M., LaRochelle, R., Arbaugh, F., \& Bieda, K. (2020). An innovative early field experience for preservice secondary teachers: Early results from shifting to an online model. Journal of Technology and Teacher Education, 28(2), 353-363.

Correia, A.-P. (2020). Finding junctures in learning design and entrepreneurship: A case of experiential learning in online education. In M. J. Bishop, E. Boling, J. Elen, \& V. Svihla (Eds.), Handbook of research on educational communications and technology. Springer Nature Switzerland AG.

Donaldson, J. P., Barany, A., \& Smith, B. K. (2020). Handbook of research on educational communications and technology: Learning design. In M. J. Bishop, E. Boling, J. Elen, \& V. Svihla (Eds.), Handbook of research on educational communications and technology: Learning design (pp. 819-835). Springer Nature Switzerland AG.

Dorner, H., \& Kumar, S. (2016). Online collaborative mentoring for technology integration in pre-service teacher education. TechTrends, 60(1), 48-55. https://doi.org/10.1007/s11528-0150016-1 
Dunlap, J. C., Verma, G., \& Johnson, H. L. (2016). Presence+experience: A framework for the purposeful design of presence in online courses. TechTrends, 60, 145-151. https://doi.org/10.1007/ s11528-016-0029-4

Garrison, D. R., Anderson, T., \& Archer, W. (2000). Critical inquiry in a text-based environment: Computer conferencing in higher education. The Internet and Higher Education, 2(2-3), 87-105 http:// dergipark.gov.tr/saufenbilder/issue/20673/220600

Garrison, D. R., \& Arbaugh, J. B. (2007). Researching the community of inquiry framework: Review, issues, and future directions. Internet and Higher Education, 10, 157-172. https://doi.org/10.1016/j. iheduc.2007.04.001

Gewertz, C. (2020). Bitmoji classrooms : Why teachers are buzzing about them. Education Week. https://www.edweek.org/teaching-learning/ bitmoji-classrooms-why-teachers-are-buzzing-about-them/2020/07

Graham, C. R., Borup, J., Short, C. R., \& Archambault, L. (2019). Personalizing instruction. In K-12 blended teaching: A guide to personalized learning and online integration. EdTech Books. https://edtechbooks.org/k12blended/personalizing_instruction

Hall, J. A. (2018). Flipping with the first principles of instruction: An examination of preservice teachers' technology integration development. Journal of Digital Learning in Teacher Education, 34(4), 201-218. https://doi.org/10.1080/21532974.2018.1494520

Hall, J. A., \& Lei, J. (2020). Conceptualization and application of a model for flipped instruction: A design case within teacher education. Research Issues in Contemporary Education, 5(2), 24-54.

Hall, J. A., Lei, J., \& Wang, Q. (2020). The first principles of instruction: An examination of their impact on preservice teachers' TPACK. Educational Technology Research and Development, 68(6), 31153142. https://doi.org/10.1007/s11423-020-09866-2

Howard, C. D., Smith, K. M., Boling, E., \& Rowland, G. (2012). Instructional design cases and why we need them. Educational Technology, June, 34-39.

International Society for Technology in Education. (2017). ISTE standards for educators. International Society for Technology in Education. https://www.iste.org/standards/for-educators

Johnson, H. L., Dunlap, J. C., Verma, G., McClintock, E., DeBay, D. J., \& Bourdeaux, B. (2019). Video-based teaching playgrounds: Designing online learning opportunities to foster professional noticing of teaching practices. TechTrends, 63(2), 160-169. https://doi. org/10.1007/s11528-018-0286-5

Keefe, E. S. (2020). Learning to practice digitally: Advancing preservice teachers' preparation via virtual teaching and coaching. Journal of Technology and Teacher Education, 28(2), 223-232.

Keller, J. M. (1987). Development and use of the ARCS model of instructional design. Journal of Instructional Development, 10(3), 2 10.

Kennedy, K., \& Archambault, L. M. (2012). Offering preservice teachers field experiences in K-12 online learning: A national survey of teacher education programs. Journal of Teacher Education, 63(3), 185-200. https://doi.org/10.1177/0022487111433651

Kimmons, R. (2020). Copyright and open licensing. In A. OttenbreitLeftwich \& R. Kimmons (Eds.), The K-12 educational technology handbook. EdTech Books. https://edtechbooks.org/k12handbook/ copyright

Kolb, D. A. (1984). Experiential learning theory. Prentice Hall.

Langub, L. W., \& Lokey-Vega, A. (2017). Rethinking instructional technology to improve pedagogy for digital literacy: A design case in a graduate early childhood education course. TechTrends, 61(4), 322330. https://doi.org/10.1007/s11528-017-0185-1

Lei, J. (2009). Digital natives as preservice teachers: What technology preparation is needed? Journal of Computing in Teacher Education, 25(3), 87-97.
Liao, Y.-C. J. (2020). Open educational resources. In A. OttenbreitLeftwich \& R. Kimmons (Eds.), The K-12 educational technology handbook. EdTech Books https://edtechbooks.org/k12handbook/ oer

Mayer, R. E., \& Moreno, R. (2003). Nine ways to reduce cognitive load in multimedia learning. Educational Psychologist, 38(1), 43-52. https://doi.org/10.1207/S15326985EP3801

Merrill, M. D. (2012). First principles of instruction (1st ed.). Pfeiffer.

Molnar, A., Miron, G., Elgeberi, N., Barbour, M. K., Huerta, L., Shafer, S. R., \& Rice, J. . (2019). Virtual schools in the U.S. 2019. https:// nepc.colorado.edu/publication/virtual-schools-annual-2019

Moore-Adams, B. L., Jones, W. M., \& Cohen, J. (2016). Learning to teach online: A systematic review of the literature on K-12 teacher preparation for teaching online. Distance Education, 37(3), 333348. https://doi.org/10.1080/01587919.2016.1232158

Morgan, K. (2008). Experiential learning. In J. M. Spector, M. D. Merrill, J. J. G. van Merriënboer, \& M. P. Driscoll (Eds.), Handbook of research on educational communications and technology (3rd ed., pp. 33-37). Lawrence Erlbaum Assoc.

Pulham, E., \& Graham, C. R. (2018). Comparing K-12 online and blended teaching competencies: A literature review. Distance Education, 39(3), 411-432.

Ritzhaupt, A. D., Valle, N., \& Sommer, M. (2020). Design, development, and evaluation of an online statistics course for educational technology doctoral students: A design and development case. Journal of Formative Design in Learning. https://doi.org/10.1007/s41686-02000051-5

Shea, P., \& Bidjerano, T. (2008). Measures of quality in online education: An investigation of the community of inquiry model and the net generation. Journal of Education Computing Research, 39(4), 339-361. https://doi.org/10.2190/EC.39.4.b

Shea, P., Vickers, J., \& Hayes, S. (2010). Online instructional effort measured through the lens of teaching presence in the community of inquiry framework: A re-examination of measures and approach. International Review of Research in Open and Distance Learning, 11(3), 127-154.

Siemens, G., Gašević, D., \& Dawson, S. (2015). The history and state of blended learning. In preparing for the digital university: A review of the history and current state of distance, blended, and online learning.

Svihla, V., \& Boling, E. (2020). Introduction to design case chapters. In M. J. Bishop, E. Boling, J. Elen, \& V. Svihla (Eds.), Handbook of research on educational communications and technology: Learning design (pp. 629-645). Springer Nature.

Trust, T., \& Whalen, J. (2020). Should teachers be trained in emergency remote teaching? Lessons learned from the COVID-19 pandemic. Journal of Technology and Teacher Education, 28(2), 189-199 https://www.learntechlib.org/primary/p/215995/

Virtual Learning Leadership Alliance, \& Quality Matters. (2019). National standards for quality online teaching. https://www.nsqol. org/the-standards/quality-online-teaching/

West, R. E., Jay, J., Armstrong, M., \& Borup, J. (2017). "Picturing them right in front of me": Guidelines for implementing video communication in online and blended learning. TechTrends, 61(5), 461-469. https://doi.org/10.1007/s11528-017-0208-y

Wilson, M. L., Ritzhaupt, A. D., \& Cheng, L. (2020). The impact of teacher education courses for technology integration on pre-service teacher knowledge: A meta-analysis study. Computers and Education, 156(May), 103941. https://doi.org/10.1016/j.compedu. 2020.103941

Publisher's Note Springer Nature remains neutral with regard to jurisdictional claims in published maps and institutional affiliations. 